\title{
Perspectives on Salutogenesis of Scholars Writing in French
}

\author{
Mathieu Roy, Mélanie Levasseur, Janie Houle, Claire Dumont, \\ and Isabelle Aujoulat
}

\section{Introduction}

In this chapter, we present the concept of salutogenesis with respect to literature produced by French-speaking researchers worldwide. Toward this goal, a nonexhaustive review of the literature was conducted. The results of our search are presented in the first section of this contribution. The evolution of this concept, and its contribution to the emergence of a new field of research, is then discussed.

Salutogenesis and its theory (i.e., sense of coherence, generalized resistance resources, and stressors) have been explored by French-speaking researchers. To locate this

\section{Roy (ه)}

Assistant General Direction, Eastern Townships Integrated University Centre for Health and Social Services-Sherbrooke Hospital University Centre, Sherbrooke, Québec, Canada

Department of Family Medicine and Emergency Medicine, Faculty of Medicine and Health Sciences, Université de Sherbrooke, Sherbrooke, Québec, Canada

e-mail: mathieu.roy7@usherbrooke.ca

\section{Levasseur}

Research Centre on Aging, Eastern Townships Integrated University Centre for Health and Social Services-Sherbrooke Hospital University Centre, Sherbrooke, Québec, Canada

Faculty of Medicine \& Health Sciences, School of rehabilitation, Université de Sherbrooke, Sherbrooke, Québec, Canada

e-mail: Melanie.levasseur@usherbrooke.ca

\section{J. Houle}

Department of Psychology, Faculty of Human Sciences, Université du Québec à Montréal, Montréal, Québec, Canada

e-mail: houle.janie@uqam.ca

\section{Dumont}

Department of Occupational Therapy, University du Québec à

Trois-Rivières, Trois-Rivières, Québec, Canada

e-mail: Claire.Dumont@uqtr.ca

\section{Aujoulat}

Faculty of Public Health, Institute of Health and Society, Université Catholique de Louvain, Brussels, Belgium

e-mail: isabelle.aujoulat@uclouvain.be literature, we searched for specific keywords (i.e., salutogenesis, salutogenic, Antonovsky, and sense of coherence) across different databases (e.g., Medline, PubMed, PsychInfo, Cinahl, Francis, and Google scholar) in French, but also in English to locate French-speaking researchers who chose to publish their work in English. This search was completed by examining references of resulting hits. This procedure has highlighted a literature on salutogenesis in the fields of (1) psychometrics, (2) health psychology, (3) health promotion, (4) rehabilitation, (5) interior design, and (6) management.

\section{Salutogenesis in the Psychometrics Domain}

The questionnaires SOC-13 and SOC-29 were translated and validated on 647 adults living in France (Gana \& Garnier, 2001). Both scales have satisfactory reliability as well as convergent and discriminant validity with depression, anxiety, and self-actualization. Factor analyses indicated that both scales contained three dimensions (Gana \& Garnier, 2001), as proposed by Antonovsky (1979). The SOC-13 was also translated and validated on French-speaking adults of the Province of Quebec in Canada (Dumont, 2003). This study demonstrated good internal consistency of the questionnaire (Cronbach's $\alpha$ : 0.83-0.90), test-retest reliability, and convergent validity with anxiety, social networks, and locus of control (Dumont, 2003). However, and opposite to Gana and Garnier (2001), factor analyses showed a unidimensional scale rather than a multidimensional one (Dumont, 2003).

\section{Salutogenesis in the Health Psychology Domain}

Conceptualizing health as the product of biological, psychological, and social processes (Johnston, 1994; Ogden, 2012), health psychology emerged as a discipline during 
the same period as did salutogenesis. Studies in this field found that the sense of coherence mediates associations between negative experiences such as childhood trauma (Fossion et al., 2014) or stressful events (Gana, 2001), and psychological distress, depression, and anxiety among adults from France. Other studies in France found that higher sense of coherence scores were correlated with greater psychological well-being (Lambert, Étienne, \& Fontaine, 2001), whereas lower sense of coherence scores predicted higher anxiety among new retirees (Gana et al., 2009a). Moreover, two main domains of research that contribute to our understanding of what creates health are currently developed in France. On the one hand, resiliency is a research arena that has been promoted by Boris Cyrulnik for many years (Cyrulnik, 2001, 2011). On the other hand, positive psychology is an emerging discipline with recent work carried out by Rebecca Shankland and colleagues (Shankland, 2014; Shankland \& MartinKrumm, 2012). Both domains focus on health assets and protective factors, and share orientations similar to that of salutogenesis.

\section{Salutogenesis in the Health Promotion Domain}

Health promotion aims to enable people, and communities, to increase control over their own health (WHO, 1986). This field differs from surveillance, protection, and prevention because it primarily addresses health and well-being rather than disease. The links between salutogenesis and health promotion are among the stronger (CIHI, 2009; Roy, 2013; Roy \& O’Neill, 2012). French-speaking researchers in this field have positioned salutogenesis as a protective factor against negative mental health outcomes (Gana \& Mezred, 2009; Koleck, Bruchon-Schweitzer, \& Bourgeois, 2003). Other researchers used the salutogenic theory to examine the impact that perceived control over one's environment might have on health (Loslier, 1996), the relevance of generalized resistance resources to produce health (Shankland \& Lamboy, 2011), and the effect of stress on health of adults living in France (Ville \& Khat, 2007). The sense of coherence was also studied as a resource to cope with breast cancer and to retrieve a positive sexual life after mastectomy (Quintard, Constant, Lakdja, \& Labeyrie-Lagardère, 2014). Moreover, the original work of Lindström and Eriksson (2008) entitled Hitchhiker's Guide to Salutogenesis: Salutogenic Pathways to Health Promotion was translated and adapted into French (Roy \& O'Neill, 2012). This book addresses salutogenesis and its theory with respect to their contribution to health promotion.

\section{Salutogenesis in the Rehabilitation Domain}

Salutogenesis also entered the field of rehabilitation, a medical specialty concerned with promoting cognitive and physical functioning. Rehabilitation makes a significant contribution to reduction of disease burden and to empowering people with different disabilities (Rochette, Korner-Bitensky, \& Levasseur, 2006; Thomas, 1999; Townsend, 2003). In this field, Provencher and Keyes (2010) proposed a salutogenic view of mental health rehabilitation. Indeed, because the recovering process was more important than its outcome, they supported that rehabilitation efforts should be placed on transformations that occurred throughout recovery (or on factors that facilitate it). In one study which involved adults living with cerebral traumas in the province of Quebec in Canada, Dumont (2003) observed that the sense of coherence was associated with social participation despite limitations. Finally, one qualitative study with 18 Quebec free-living older adults having various levels of disabilities identified personal factors such as inner life, adaptation, and sense of control over one's own life, as general resistance resources for better quality of life (Levasseur, St-Cyr Tribble, \& Desrosiers, 2009).

\section{Salutogenesis in the Interior Design Domain}

Salutogenesis is also presented in the field of interior design. In one exploratory study undertaken with older adults in a Quebec long-term healthcare center, Boisclair (2013) examined the role of indoor planning to create healing environments. It was found that housing conditions that are conducive to interactions, support, pleasure, reflection, intimacy, and empowerment may be relevant to experience successful aging.

\section{Salutogenesis in the Management Domain}

We identified one study wherein salutogenesis was applied to management. In this study, the author examined which resources may help businessmen to create jobs and industries despite unfavorable economic contexts and stressors related to this work (Gharbi, 2013).

\section{Summary of the Francophone Literature on Salutogenesis}

According to the literature reviewed above, there is a relatively small body of knowledge on salutogenesis among worldwide French-speaking communities. In Francophony, more literature comes from European countries (i.e., France) 
or from the Province of Quebec in Canada. This may be due to Antonovsky's European origin, to the origins of researchers writing in French, and/or to different socioeconomic realities.

The relative scarcity of French literature on salutogenesis may also be the result of a language bias. No matter where French-speaking researchers live, they may pragmatically choose to publish their work in English. Only a few papers with original results were identified in this review. French literature on salutogenesis is in fact more theoretical than practical. However, and because it leads to the emergence of a new field of research among French-speaking communities (i.e., positive approaches to health), such theoretical contribution is important.

\section{The Evolution of Salutogenesis}

Salutogenesis has evolved since its creation. It was established in opposition to pathogenesis to highlight that studies were too oriented toward diseases (or risk factors) rather than to focus on health, resources or capabilities (Antonovsky, 1979). To operationalize this concept, Antonovsky created the salutogenic theory. He explained that stressors were pervasive in life. He stated that under the influence of stressors, people experience tensions. They either fall prey to these tensions or learn to cope with them (Antonovsky, 1987). To cope with tensions, people use GRR. Along the famous health ease-disease continuum (Lindström \& Eriksson, 2008), Antonovsky defined salutogenesis as the movement toward the positive pole of this continuum. To capture this movement, Antonovsky created the SOC questionnaires (Antonovsky, 1993). A stronger score to these questionnaires was predictive of this movement (Eriksson, Lindström, \& Lilja, 2007). To summarize, GRR are moderators in associations between stressors and SOC (Roy, 2013).

Salutogenesis, however, should mean more than just studying the sense of coherence (Lindström \& Eriksson, 2008). Salutogenesis calls also for a focus on resources, skills, capabilities, strengths, and assets at different levels (e.g., people, community, and society; Dumont, Gervais, Fougeyrollas, \& Bertrand, 2004; Roy \& O’Neill, 2012). Following this thought, Lindström and Eriksson (2008) introduced a salutogenic perspective under a salutogenic umbrella where all theories and/or concepts in relation with positive health were gathered. This evolution from a concept, to a theory, toward an encompassing orientation, brought the conditions to move forward with a new field of research in Frenchspeaking countries.

\section{The Field of Positive Approaches to Health}

The field of positive approaches to health, such as salutogenesis, focuses on why some people thrive or stay healthy as opposed to others who get sick. One example of a positive approach to health is to increase resilience (Friedli, 2009). In addition to resilience or salutogenesis, there are many other positive approaches to health, for example, quality of life, cultural and social capital, social participation, self-efficacy, empowerment, connectedness, hardiness, and flourishing (Lindström \& Eriksson, 2008). Each of these approaches use different constructs to operationalize their own theory. However, they aim for the same outcome: increased well-being. This emerging field of research has even been named by the World Health Organization the "asset-based approach" (Morgan \& Ziglio, 2007). Salutogenesis might have contributed to the emergence of this field of research in French-speaking countries. Indeed, many researchers are now shifting from models studying deficiency, disease, and incapacity to alternative models focused on health, human development, and social participation (Fougeyrollas, 1997, 2010; Fougeyrollas et al., 1996).

There are examples of research using positive approaches to health in French-speaking countries, using various approaches to address Antonovsky's question about what creates health.

Promoting older adults' social participation The burden of chronic illnesses places an unsustainable strain on healthcare systems, which is accentuated by aging. To act upstream, a coauthor of this chapter is currently working to implement innovative interventions to optimize older adults' social participation (Levasseur et al., 2015; Levasseur \& Couture, 2015). Levasseur's research aims to create an index of social participation potential to guide decisions and optimize environments (Levasseur et al., 2012), to adapt a personalized attendant to community integration, and to increase awareness of older adults with a tool on skills required and compensatory strategies for safe and responsible automobile driving (Levasseur et al., 2015).

Monitoring positive health indicators Eastern Townships are a Quebec (Canada) health region with almost 500,000 inhabitants living in urban, semiurban, and rural communities. In 2014, public health authorities of this region conducted a representative population-based survey among 8,737 adults to monitor the physical and mental health of their population. Capitalizing on this opportunity, the first two authors of this chapter, with other colleagues, were able to include positive health measures (i.e., resilience, social participation, and positive mental health) in 
this survey. Their objectives were to (1) assess the social and geographic distribution of positive health indicators at a regional scale, (2) examine associations between such measures and various aspects of the environment, (3) estimate the prevalence of such positive health measures at a local scale, and (4) examine the mediating-moderating role of such positive health indicators in associations between negative health and the use of healthcare services. By adding such positive health indicators, this research will help regional public health authorities to strengthen their surveillance system and to tailor their interventions to reduce health inequalities.

\section{Conclusion}

In this contribution, we reviewed literature on salutogenesis among French-speaking countries and/or researchers. Our results highlight a relative scarcity of this literature. Nevertheless, our results also reveal a theoretical contribution of salutogenesis to various scientific disciplines, as evidenced by the publications of a number of French-speaking scientists and clinicians in the field of health promotion, health psychology, rehabilitation, and so on. Salutogenesis has moved from an original concept, to a well-established theory, toward a unifying orientation, which finally unlocked a new field of research worldwide (i.e., positive approaches to health). French-speaking countries slowly, but surely, use this road to create health. We think this is an important contribution of Antonovsky's legacy to Francophone health promotion.

Open Access This chapter is distributed under the terms of the Creative Commons Attribution-Noncommercial 2.5 License (http:// creativecommons.org/licenses/by-nc/2.5/) which permits any noncommercial use, distribution, and reproduction in any medium, provided the original author(s) and source are credited.

The images or other third party material in this chapter are included in the work's Creative Commons license, unless indicated otherwise in the credit line; if such material is not included in the work's Creative Commons license and the respective action is not permitted by statutory regulation, users will need to obtain permission from the license holder to duplicate, adapt or reproduce the material.

\section{References}

Antonovsky, A. (1979). Health, stress and coping. San Francisco, CA Jossey-Bass.

Antonovsky, A. (1987). Unraveling the mystery of health: How people manage stress and stay well. San Francisco, CA: Jossey-Bass.

Antonovsky, A. (1993). The structure and properties of the sense of coherence scale. Social Science \& Medicine, 36, 725-733.

Boisclair, C. (2013). Aménagement intérieur des milieux de santé: Exploration de trois approches théoriques. Unpublished master's thesis for master's degree, Université de Montréal, Montréal, Québec, Canada. [In French].
Canadian Institute on Health Information (CIHI). (2009). Améliorer la santé des Canadiens: Explorer la santé mentale positive. Ottawa, Ontario, Canada. [In French].

Cyrulnik, B. (1999). Un merveilleux malheur. Éditions Odile Jacob. [In French].

Cyrulnik, B. (2001). Les vilains petits canards. Éditions Odile Jacob. [In French].

Cyrulnik, B. (2011). Resilience: How your inner strength can set you free from the past. Tarcher Editions.

Dumont, C. (2003). L'identification des facteurs qui vont favoriser la participation sociale des adultes présentant des séquelles de traumatisme cranio-cérébral. Unpublished doctoral dissertation, Université de Laval, Quebec city, Québec, Canada. [In French].

Dumont, C., Gervais, M., Fougeyrollas, P., \& Bertrand, R. (2004). Toward an explanatory model of social participation for adults with traumatic brain injury. Journal of Head Trauma and Rehabilitation, 19, 431-444.

Eriksson, M., Lindström, B., \& Lilja, J. (2007). A sense of coherence and health. Salutogenesis in a societal context: Aland, a special case? Journal of Epidemiology \& Community Health, 61, 684-688.

Fossion, P., Leys, C., Kempenaers, C., Braun, S., Verbanck, P., \& Linkowski, P. (2014). Disentangling sense of coherence and resilience in case of multiple traumas. Journal of Affective Disorders, $160,21-26$.

Fougeyrollas, P. (1997). Les déterminants environnementaux de la participation sociale des personnes ayant des incapacités: Le défi socio-politique de la révision de la CIDIH. Revue Canadienne de ré adaptation, 10, 147-160 [In French].

Fougeyrollas, P. (2010). La Funambule, le fil et la toile. Québec, Canada: Les Presses de l'Université Laval [In French].

Fougeyrollas, P., Cloutier, R., Bergeron, H., Côté, J., Côté, M., \& St-Michel, G. (1996). Révision de la proposition québécoise de classification: Processus de production du handicap. Québec, Canada: Réseau international sur le processus de production du handicap [In French].

Friedli, L. (2009). Mental health, resilience and inequalities. Denmark: World Health Organisation Regional Office for Europe.

Gana, K. (2001). Is sense of coherence a mediator between adversity and psychological well-being in adults? Stress \& Health, 17, 77-83.

Gana, K., Blaison, C., Boudjemadi, V., Mezred, D., K’Delant, P., Trouillet, R., et al. (2009). Étude de quelques déterminants de l'anxiété face au passage à la retraite. Canadian Journal of Behavioural Sciences, 41, 260-271 [In French].

Gana, K., \& Garnier, S. (2001). Latent structure of the sense of coherence scale in a French sample. Personality and Individual Differences, 31, 1079-1090.

Gana, K., \& Mezred, D. (2009). Tracasseries quotidiennes, réminiscence et santé mentale chez l'adulte et la personne âgée : Test d'un modèle structural des effets médiateurs de la réminiscence. Psychologie Française, 54, 211-224 [In French].

Gharbi, V. (2013). La dimension santé dans les structures d'accompagnement à la création d'entreprise: une perspective salutogène. Unpublished doctoral dissertation, Université de Montpellier 1, Montpellier, France. [In French].

Johnston, M. (1994). Current trends in health psychology. The Psychologist, 7, 114-118.

Koleck, M., Bruchon-Schweitzer, M., \& Bourgeois, M. L. (2003). Stress et coping: Un modèle intégratif en psychologie de la santé. Annales Médico Psychologiques, 161, 809-815 [In French].

Lambert, S., Étienne, A. M., \& Fontaine, O. (2001). Sens de la cohérence, colère et trouble obsessionnel-compulsif. Revue francophone de clinique comportementale et cognitive, 6, 5-16 [In French].

Levasseur, M., Audet, T., Gélinas, I., Bédard, M., Langlais, M. E., Therrien, F. H., et al. (2015). Awareness tool for safe and responsible driving (OSCAR): A potential educational intervention for 
increasing interest, openness and knowledge about the abilities required and compensatory strategies among older drivers. Traffic Injury Prevention, 16, 578-586.

Levasseur, M., \& Couture, M. (2015). Coping strategies associated with participation and quality of life in older adults. Canadian Journal of Occupational Therapy, 82, 44-53.

Levasseur, M., St-Cyr Tribble, D., \& Desrosiers, J. (2009). Meaning of quality of life for older adults: Importance of human functioning components. Archives of Gerontology and Geriatrics, 49, e91-e100.

Levasseur, M., Vanasse, A., Courteau, J., Généreux, M., Cohen, A., \& Kestens, Y. (2012). Favoriser la participation sociale et la santé de la population vieillissante grâce aux enquêtes populationnelles et à la géomatique: Un exemple d'une initiative méthodologique possible. Médecine Sciences Amérique, 1, 55-61 [In French].

Lindström, B., \& Eriksson, M. (2008). The hitchhiker's guide to salutogenesis: Salutogenic pathways to health promotion. Helsinki, Finland: Tuokinprint Oy.

Loslier, L. (1996). Santé et environnement, du collectif à la personneAnalyse de données québécoises et proposition théorique. Actes du colloque de l'association internationale des démographes de langue française. 291-301. [In French].

Morgan, A., \& Ziglio, E. (2007). Revitalising the evidence base for public health: An assets model. Promotion \& Education, 2, S17-S22.

Ogden, J. (2012). Health psychology: A textbook (5th ed.). Maidenhead, UK: Open University Press.

Provencher, H., \& Keyes, C. L. M. (2010). Une conception élargie du rétablissement. L'Information Psychiatrique, 86, 579-589 [In French].

Quintard, B., Constant, A., Lakdja, F., \& Labeyrie-Lagardère, H. (2014). Factors predicting sexual functioning in patients 3 months after surgical procedures for breast cancer: The role of the Sense of Coherence. European Journal of Oncology Nursing, $18,41-45$.

Rochette, A., Korner-Bitensky, N., \& Levasseur, M. (2006). Optimal participation: A reflective look. Disabilily \& Rehabilitation, 28, 1231-1235.

Roy, M. (2013). Pour une promotion de la santé: La salutogenèse. Spiritualitésanté, 6, 44-47 [In French].

Roy, M., \& O’Neill, M. (2012). La salutogénèse: Petit guide pour promouvoir la santé (p. 109p). Québec, Canada: Les Presses de l’Université Laval [In French]. ISBN 978-2-7637-9683-3.

Shankland, R. (2014). La psychologie positive. Paris: Éditions Dunod [In French].

Shankland, R., \& Lamboy, B. (2011). Utilité des modèles théoriques pour la conception et l'évaluation de programmes en prévention et promotion de la santé. Pratiques Psychologiques, 17, 153-172 [In French].

Shankland, R., \& Martin-Krumm, C. (2012). Évaluer le fonctionnement optimal: Échelles de psychologie positive validées en langue française. Pratiques Psychologiques, 18, 171-187 [In French].

Thomas, J. J. (1999). Enhancing patient education: Addressing the issue of literacy. Physical Disabilities Special Interest Section Quarterly, 22, 3-4.

Townsend, E. (2003). Reflections on power and justice in enabling occupation. Canadian Journal of Occupational Therapy, 70, 74-87.

Ville, I., \& Khat, M. (2007). Meaning and coherence of self and health: An approach based on narratives of life events. Social Science \& Medicine, 64, 1001-1014.

World Health Organization (WHO). (1986). Ottawa charter for health promotion. Geneva, Switzerland: World Health Organization. 